\title{
NEWS IN BRIEF
}

\section{Game Changer Diagnostic Test for Tuberculosis}

Suzanne Anderson from the University of Sussex looked at specific signatures (RNA transcripts) in 51 genes in the blood samples of children with sputum positive tuberculosis in South Africa and Malawi. The presence of these signatures in 42 genes helped them distinguish active tuberculosis from both latent tuberculosis and the absence of tuberculosis. To further validate the test, they looked for this particular signature in other groups of children with confirmed or suspected tuberculosis. The score had a sensitivity of $82.9 \%$ and a specificity of $83.6 \%$ for discriminating cultureconfirmed tuberculosis from other diseases in children with or without HIV coinfection. The test also distinguished latent from active tuberculosis with a sensitivity of $94 \%$ and specificity of $100 \%$. The Xpert Mtb/Rif PCR test on respiratory samples of these patients - on the other hand had a sensitivity of only $54.3 \%$. Although the preliminary results sound exciting, the technology is expensive and complex, and there is still an onerous road from the laboratory to the bedside. (NEngl J Med. 2014;370:1712)

\section{The Dilemma of Unbanked Blood}

Due to extreme shortage of banked blood in the country especially rural areas - activists, including the Association of Rural Surgeons of India, have been fighting for direct donor-to-patient blood. This was legal till the 1999 amendment of the Drugs and Cosmetics Act 1945. In unbanked donor blood transfusion (UDBT), the donor is tested for all regular pathogens, including HIV. After grouping and cross matching, the blood is directly transfused from donor to patient without storing in a blood bank. Appropriate collection and transfusion equipment has to be used, and the blood has to be maintained at the right temperature. In remote areas, UDBT is often critical in saving lives after massive hemorrhage due to trauma or childbirth.

The rules to set up a blood bank are often unattainable in many parts of the country. Existing rules demand that blood banks should have seven rooms, of which four should be air-conditioned, with round-the-clock power supply, specially designed refrigerators and other sophisticated equipment managed by a medical officer and full-time technical staff. There are only 2545 licenced blood banks in the country with about $30 \%$ deficit of blood at the national level. Indian law currently allows UDBT only for the armed forces.

UDBT also has the approval of the WHO. However in a recent decision, the Drugs and Technical Advisory Board of the Centre has decided to continue to ban unbanked blood transfusions. Reasons for this are mainly the concern regarding transfusion-related infections (http:// www.downtoearth.org.in/content/drugs-advisory-boardsays-no-direct-blood-transfusion)

\section{Midde-East Respiratory Syndrome}

There has been a surge of cases - mainly in the Middle-East - of the Middle-East Respiratory Syndrome (MERS). This acute respiratory illness mimics Severe Acute Respiratory Syndrome (SARS), and is also caused by a coronavirus. It has nearly $30 \%$ mortality, and is believed to have originated in camels. It is suspected that milking a camel produces a fine frothy aerosol from which the virus is inhaled and transmitted to humans. With pilgrims pouring into Makkah and Madinah for Umrah, local authorities are gearing up to prevent transmission. Isolated reports of the infection have been documented in individuals who had travelled from the Middle East. However, an emergency meeting of the WHO's Emergency Committee for MERS decided that it did not meet "Public Health Emergency of International Standards." (The Hindu 15 May 2013)

\section{Hitting OUT ON Tobacco}

One thousand billion rupees are estimated to be spent in India in 2011 on health expenditure due to tobacco-related illnesses. Out of 1 million tobacco-related deaths in India, $27 \%$ occur in the age group of $15-24$ years. About $35 \%$ of India's adult population is addicted to some form of tobacco.

On 31st May - World No Tobacco Day - the WHO called upon all countries to raise taxes on tobacco. It estimates that raising taxes by $50 \%$ will reduce users by 49 million and save 11 million lives over 3 years. Between 1990 and 2005, France tripled its inflation adjusted cigarette prices, and consequently sales fell by $50 \%$. Now France has also recorded a visible decline in deaths due to tobacco. On World Tobacco day, the Indian Government will release a hard hitting 4 minute film "The Price We Pay." This includes footage from Tata Memorial hospital's Cancer Ward to show how tobacco can destroy individuals and families. Targeting adolescents will be a key strategy if the Government really aims to reduce prevalence by $15 \%$ by 2020 and $30 \%$ by 2025. (The Hindu 4 June 2014, The Hindu 7 June 2014, http://www.who.int/mediacentre/news/ releases/2014/no-tobacco-day/en/)

Gouri Rao Passi gouripassi@hotmail.com 